\title{
Development and validation of a stability indicating HPLC-diode array-fluorescence method for the determination of meclofenoxate hydrochloride and $p$-chlorophenoxyacetic acid
}

\author{
Marwa Said Moneeb*, Feda Elgammal, Suzy Mohamed Sabry \\ Department of Pharmaceutical Analytical Chemistry, Faculty of Pharmacy, University of Alexandria, Alexandria, Egypt.
}

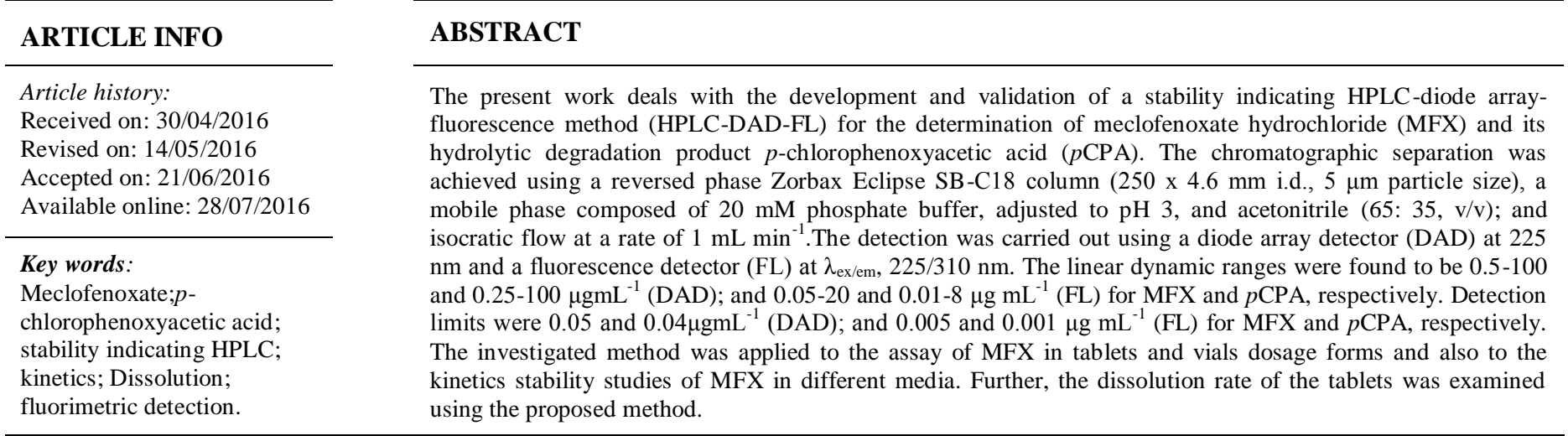

\section{INTRODUCTION}

Meclofenoxate hydrochloride (MFX), (4chlorophenoxy)-acetic acid 2-(dimethylamino) ethyl ester hydrochloride (Sweetman, 2009), is a cerebral stimulant. It acts as a nootropic agent used to treat symptoms of senile dementia and alzheimer's disease (Marcer and Hopkins, 1977; Wood and Peloquin, 1982).

MFX is not official in the British Pharmacopoeia (BP) and the United States Pharmacopeia (USP). Several analytical techniques have been reported for the analysis of MFX, including: HPLC methods (Cooke et al., 1979; Tatsuhara and Tabuchi, 1980; Yoshioka et al., 1982; Yoshioka et al., 1983; Ohta et al., 1986; El-Bardicy et al., 2007 a; Ling-yun et al., 2007), voltammetry using novel sensor based on gold nano-

* Corresponding Author

Marwa S. Moneeb, Department of Pharmaceutical Analytical Chemistry, Faculty of Pharmacy, University of Alexandria, Alexandria, Egypt.

Tel: +2034871317; E-mail: marwamoneeb@yahoo.com particles (Li et al., 2012), potentiometry (El-Bardicy et al., 2007 b;El-Nashar et al., 2012), resonance Rayleigh scattering method (Hu et al., 2010), proton magnetic resonance spectroscopy (Shoukrallah et al., 1990; Zhang et al., 2016), spectrophotometry (Fecko, 1973; Araman et al., 1992), radiochemistry (Cecal et al., 1983) and microcalorimetry (Otsuka et al., 1994). MFX is an ester drug, it is highly susceptible to hydrolysis in aqueous solution to give hydrolytic products, $p$-chlorophenoxyacetic acid ( $p$ CPA) and $\mathrm{N}$, N-dimethyl ethanol amine (Cooke et al., 1979). Several studies have handled the stability of MFX in aqueous and/or non-aqueous solutions (Cooke et al., 1979; Tatsuhara and Tabuchi, 1980; Yoshioka et al., 1982; Yoshioka et al., 1983; Ohta et al., 1986; Araman et al., 1992; Otsuka et al., 1994; El-Bardicy et al., 2007 a; El-Bardicy et al., 2007 b; El-Nashar et al., 2012), however some of the results of these investigations are contradicted. The inconsistency around stability data was the motivator for the present work. The present work describes an HPLC-diode arrayfluorescence (HPLC-DAD-FL) method for the determination of $\mathrm{MFX}$ and $p \mathrm{CPA}$. 
To our knowledge, no HPLC-fluorescence detection method has been reported for the determination of MFX or $p$ CPA. The first target of this work was to establish stability indicating assay method, so the method was applied to study the forced hydrolytic, oxidative and photolytic degradation of MFX. MFX showed good resolution from all degradation products. It should be noted that the other reported methods have considered only the hydrolytic degradation.

Another target was to apply the developed method to the kinetic stability study of MFX, to investigate its half-life time in aqueous and non aqueous solutions to give enough information about the most appropriate solvent for the stability of MFX standard solutions and the best $\mathrm{pH}$ for analytical method optimization. Also, the method was applied to the determination of MFX and its degradation product, $p$ CPA in pharmaceutical formulations and for MFX tablets dissolution testing.

\section{MATERIALS AND METHODS}

\section{Instrumentation}

The HPLC equipment was Agilent 1200 series (Agilent Technologies, Santa Clara, CA, USA) (quaternary pump, vacuum degasser) with auto-sampler (G13298 1260 series ALS) and two detectors: diode array and multiple wavelength detector (G1315 C/D and G1365 C/D); and a fluorescence detector (G1321C 1260 series FLD) connected to a computer loaded with Agilent ChemStation Software. The column used was Zorbax Eclipse SBC18 (250 x $4.6 \mathrm{~mm}$ i.d., $5 \mu \mathrm{m}$ particle size) Agilent. The flow rate was maintained at $1 \mathrm{~mL} \mathrm{~min}^{-1}$ and the injection volume was $20 \mu \mathrm{L}$. The mobile phase was prepared daily, filtered through a $0.45 \mu \mathrm{m}$ membrane filter.

The photo-degradation was carried out using an ultra violet lamp of the Horizontal Laminar Flow Clean Work Bench modelNU-201 and NU-201(E).

The dissolution testing of MFX Lucidril ${ }^{\circledR}$ tablets was performed on a six station dissolution apparatus, Hanson Research Corp., Northridge California,USA.

\section{Materials and reagents}

Authentic sample of MFX,98\% was purchased from Alfa Aesar, a Johnson Matthey Company, Karlsruhe, Germany. Lucidril $^{\circledR}$ tablets labeled to contain $250 \mathrm{mg}$ MFX per tablet and Luciforte $^{\circledR}$ vials labeled to contain $500 \mathrm{mg}$ MFX per vial, both are manufactured by Minapharm, Egypt and purchased from local market. HPLC grade acetonitrile and methanol were purchased from LAB- SCAN Analytical Sciences, Poland. HPLC grade $o$ phosphoric acid (LOBA chemie PVT-LTD. Mumbai, India) was used. Disodium hydrogen phosphate, sodium hydroxide, hydrochloric acid, 30\% hydrogen peroxide were of analytical grade. High purity distilled water was used.

\section{Chromatographic conditions}

The chromatographic separation was performed using a reversed phaseZorbax Eclipse SB-C18 column (250 x 4.6 mm i.d.,
$5 \mu \mathrm{m}$ particle size) Agilent maintained at $25^{\circ} \mathrm{C}$, eluted with mobile phase at a flow rate of $1 \mathrm{~mL} \mathrm{~min}^{-1}$. The mobile phase consisted of $20 \mathrm{mM}$ phosphate buffer adjusted to $\mathrm{pH} 3$ (using $o$-phosphoric acid) and acetonitrile (65: $35, \mathrm{v} / \mathrm{v})$, filtered prior to use through $0.45 \mu \mathrm{m}$ nylon filter and degassed prior to use. The injection volume was $20 \mu \mathrm{L}$. The eluents were monitored using DAD at 225 $\mathrm{nm}$ and FL at $\lambda_{\mathrm{ex} / \mathrm{em}}, 225 / 310 \mathrm{~nm}$.

\section{Preparation of $p \mathrm{CPA}$}

$p$ CPA was prepared by alkaline hydrolysis of MFX using $2 \mathrm{M} \mathrm{NaOH}$ following the reported method (El-Bardicy et al., 2007 a).

\section{Preparation of solutions \\ Preparation of stock and working standard solutions}

Stock solution of $1000 \mu \mathrm{gmL}^{-1}$ of MFX in $0.1 \mathrm{M} \mathrm{HCl}$ was prepared and kept in the refrigerator. Working standard solutions were prepared by suitable dilution with the mobile phase to cover the concentration range of $0.5-100 \mu \mathrm{g} \mathrm{mL}^{-1}$ and $0.05-20$ $\mu \mathrm{g} \mathrm{mL} \mathrm{L}^{-1}$ for DAD and FL, respectively. The stock solution should be freshly prepared daily.

Stock solution of $1000 \mu \mathrm{g} \mathrm{mL}{ }^{-1}$ of $p$ CPA was prepared by dissolving $p$ CPA powder in $2 \mathrm{~mL}$ of methanol followed by dilution with distilled water. Working standard solutions were prepared by suitable dilution with the mobile phase to cover the concentration range of $0.25-100 \mu \mathrm{g} \mathrm{mL}^{-1}$ and $0.01-8 \mu \mathrm{g} \mathrm{mL} \mathrm{m}^{-1}$ for DAD and FL, respectively.

\section{Preparation of dosage form solutions \\ Preparation of MFX tablets solution}

A total of 20 Lucidril ${ }^{\circledR}$ tablets were weighed and finely powdered. An accurate weight of the finely powdered sample equivalent to $50 \mathrm{mg}$ of MFX was extracted into about $2 \mathrm{~mL}$ methanol with the aid of sonication for $1 \mathrm{~min}$, using ultrasonic bath, then $20 \mathrm{~mL}$ of $0.01 \mathrm{M} \mathrm{HCl}$ were added and the sonication was continued for further $10 \mathrm{~min}$. The mixture was filtered into a 50-ml volumetric flask. The residue was washed with two 10-ml portions of $0.01 \mathrm{M} \mathrm{HCl}$ and washings were added to the filtrate and diluted to volume with $0.01 \mathrm{M} \mathrm{HCl}$. The concentration of this prepared assay solution is $1000 \mu \mathrm{g} \mathrm{mL}^{-1}$. Further suitable dilutions were made with the mobile phase before chromatographic analysis.

\section{Preparation of MFX vials sample solution}

Fifty $\mathrm{mg}$ from Lucifort ${ }^{\circledR}$ vial was transferred into $50-\mathrm{mL}$ volumetric flask containing about $2 \mathrm{~mL}$ of methanol. The powder was dissolved and the volume was completed with $0.01 \mathrm{M} \mathrm{HCl}$ to prepare $1000 \mu \mathrm{g} \mathrm{mL} \mathrm{mL}^{-1}$ assay vials solution. Further suitable dilutions were made with the mobile phase before chromategraphic analysis.

\section{Procedure for forced degradation study}

Forced degradation of MFX was carried out under neutral/ acid/ base hydrolytic, oxidative and photolytic stress 
conditions. MFX powder was dissolved in distilled water (for neutral hydrolysis, using $6 \mathrm{~h}$ study time), $0.1 \mathrm{M} \mathrm{HCl}$ (for acid hydrolysis, using $6 \mathrm{~h}$ study time), $0.1 \mathrm{M} \mathrm{NaOH}$ (for base hydrolysis, using 5 min study time), all kept at ambient temperature. After the degradation time specified was elapsed, a neutralization step of acidic and alkaline degraded solution was done. Chromatographic analysis of the degraded samples was carried out, taking into consideration a suitable dilution with the mobile phase, to get concentrations of 100 and $10 \mu \mathrm{gmL}^{-1} \mathrm{MFX}$ for the DAD and FL, respectively, as initial concentrations.

For the oxidative degradation, MFX drug powder was dissolved in $8 \% \mathrm{H}_{2} \mathrm{O}_{2}$ (prepared by dilution of hydrogen peroxide $30 \%$ with distilled water), and allowed for stress degradation for $24 \mathrm{~h}$ at ambient temperature. Another experiment was performed using $10 \% \mathrm{H}_{2} \mathrm{O}_{2}$ for $6 \mathrm{~h}$ at $80^{\circ} \mathrm{C}$. Chromatographic analysis of the degraded samples was carried out, taking into consideration a suitable dilution with the mobile phase, to get concentration of 500 $\mu \mathrm{gmL}^{-1} \mathrm{MFX}$ for the DAD and FL, as initial concentration.

Photo-degradation was carried out on solid drug substance and on solutions of MFX prepared in $0.01 \mathrm{M} \mathrm{HCl}$ and in distilled water. The solid and the solutions were irradiated with UV radiation having peak intensity at $254 \mathrm{~nm}$ for $3 \mathrm{~h}$. After the specified time, the mobile phase was used to reconstitute the powder and to suitably dilute the solutions in order to get concentrations of 100 and $10 \mu \mathrm{g} \mathrm{mL}^{-1} \mathrm{MFX}$ for the DAD and FL, respectively as initial concentrations.

\section{Kinetic and stability study of MFX}

Into a set of volumetric flasks, separate accurate volumes of a freshly prepared stock standard solution of MFX, $1000 \mu \mathrm{g}$ $\mathrm{mL}^{-1}$ in distilled water, were diluted with a suitable volume of the medium to be investigated, to give final concentrations of 100 and $20 \mu \mathrm{gmL}^{-1} \mathrm{MFX}$ for the DAD and FL, respectively. The kinetic studies were performed at ambient temperature. The concentration of the remaining MFX was monitored at suitable time intervals, taking into consideration that the analysed solution was double diluted with the mobile phase before chromatographic analysis.

\section{In vitro dissolution study of MFX tablets}

In vitro dissolution testing of Lucidril ${ }^{\circledR}$ tablets was performed with USP apparatus 2 (paddle method) using dissolution medium, $900 \mathrm{~mL}$ of $\mathrm{HCl}$ of $\mathrm{pH} 1.2$ as simulated gastric medium. A paddle stirrer was used for $60 \mathrm{~min}$ at a stirring rate of $100 \mathrm{rpm}$. The temperature of the cell was maintained at $37 \pm$ $0.5^{\circ} \mathrm{C}$.

Five $\mathrm{mL}$ sample aliquots were withdrawn at time intervals of $5 \mathrm{~min}$, and immediately replaced with equal volume of the fresh dissolution medium to maintain constant total volume. These aliquots were filtered with $0.45 \mu \mathrm{m}$ millipore filter and diluted 20 folds and 200 folds for DAD and FL, respectively, with the mobile phase before chromatographic analysis. The drug dissolved was calculated from chromatographic analysis data with reference to a standard MFX solution analysed in parallel. Then, the cumulative percentages of the dissolved drug were calculated.
The dissolution data were obtained by averaging three parallel studies.

\section{RESULTS AND DISCUSSION}

\section{Method development and optimization of chromatographic conditions}

In developing and optimization of the HPLC method, 3 objectives were considered; first, establishing a stability indicating method for the analysis of MFX and $p \mathrm{CPA}$, with best resolution from oxidative degradation products, second, setting conditions which favor the stability of MFX as it is highly susceptible to hydrolysis, third, maximizing the sensitivity, especially speaking, fluorescence detection.

The first study in the method development was concerned with the chromatographic separation of MFX and pCPA, using two tested columns; Zorbax SB-C8 (250 x $4.6 \mathrm{~mm})$ and Zorbax Eclipse SB-C18 (250 x $4.6 \mathrm{~mm}$ ); and a mobile phase consisting of $20 \mathrm{mM}$ acetate buffer adjusted to $\mathrm{pH} 3$ (using acetic acid) : methanol $(65: 35, \mathrm{v} / \mathrm{v})$. The results referred to un-significant difference, regarding retention, resolution and peak symmetry. The C18 column was selected for the following studies. The second study aimed to compare between $20 \mathrm{mM}$ phosphate buffer of $\mathrm{pH} 3$ and $20 \mathrm{mM}$ acetate buffer of $\mathrm{pH} 3$, both at a ratio of buffer: methanol $(65: 35, \mathrm{v} / \mathrm{v})$, The results referred to un-significant difference, regarding retention, resolution, peak symmetry and UV detection sensitivity. However, phosphate buffer showed fluorescence intensity (peak area) nearly double that of acetate buffer, so phosphate buffer was chosen as optimum for the following studies. The next study dealt with the comparison between methanol and acetonitrile as an organic modifier, both at a ratio of $20 \mathrm{mM}$ phosphate buffer of $\mathrm{pH} 3$ : organic modifier (65: 35, v/v). About $35 \%$ enhancement in FL detection was observed with acetonitrile with no noticeable difference in chromatographic performance and in UV detection sensitivity. Accordingly, acetonitrile was selected as the optimum organic modifier. Other study was performed using $20 \mathrm{mM}$ phosphate buffer of $\mathrm{pH} \mathrm{3}$, with variation of acetonitrile ratio from $25 \%$ to $60 \%$. The results showed that at acetonitrile $\%>40 \%$, shorten analysis time with poor resolution was obtained while acetonitrile $\% \leq 30 \%$ resulted in marked retardation in chromatographic separation. Accordingly, acetonitrile \% between $35 \%$ and $40 \%$ seems to be the best. Although $40 \%$ acetonitrile showed slight enhancement in FL detection, relative to $35 \%$ acetonitrile, the latter was chosen as optimum as it allows better resolution of MFX and $p$ CPA from oxidative degradation products.

The final study, in optimizing chromatographic conditions, targeted $\mathrm{pH}$. Two factors were considered, the $\mathrm{pH}$ dependent stability of MFX and the $\mathrm{pK}_{\mathrm{a}}$ of $p$ CPA (3.56). The $\mathrm{pH}$ limit for best stability of MFX could be deduced from reported first order rate constant, $\mathrm{k}\left(\mathrm{min}^{-1}\right)$ at $\mathrm{pH} 4\left(1.19 \times 10^{-4}\right)$ and $\mathrm{pH} 5$ $\left(2.39 \times 10^{-4}\right)$, both correspond to $\mathrm{t}_{90 \%} 15 \mathrm{~h}$ and $6.6 \mathrm{~h}$, respectively(Cooke et al., 1979; Ohta et al., 1986). So, working in $\mathrm{pH}$ ranged from 2 to 5 is practically possible, however, at $\mathrm{pH} 2$, 
$p$ CPA showed significant retarded elution, also at $\mathrm{pH} \geq 4$, it directed towards too early elution (ionized species predominate), resulting in poor resolution from MFX peak. Accordingly, $\mathrm{pH} 3$ was chosen as a working $\mathrm{pH}$. It was advantageous that the isocratic elution achieved good chromatographic performance and analysis time less than $20 \mathrm{~min}$ for separation of MFX from all possible degradation products. DAD was set at $225 \mathrm{~nm}$ to allow for best method sensitivity. Both MFX and $p C P A$ show strictly overlapping UV spectra showing maximum absorption at $225 \mathrm{~nm}$.

To our knowledge, no reported article has studied the native fluorescence properties of MFX to establish an analytical method. $p$ CPA is the hydrolytic product, also the active metabolite, of MFX(Cooke et al., 1979). Its structure is closely related to chlorophenoxyacetic acid herbicides. Photodegraedinduced fluorimetric methods for the determination of chlorophenoxyacetic acid herbicides have been developed (Eremin et al., 1996; Garcia et al., 1996; Garcia-Campana et al., 2001; Almansa Lopez et al., 2003). The authors have claimed that all chlorophenoxyacetic acid herbicides have no native fluorescence. However, Schussler (1990) has developed an HPLC-fluorescence detection method based on measurement of native fluorescence of chlorophenoxy derivatives, without any derivatization, in water down to ng levels. He showed that4-chloro-2methylphenoxyacetic acid and 4-chloro-2-methylphenoxybutanoic acid are natively fluorescent species, while 2,4dichlorophenoxyacetic acid and 2,4-dichlorophenoxybutanoic acid are not fluorescent. The present work targeted the native fluorescence of MFX and $p \mathrm{CPA}$ to establish a new analytical HPLC-FL method. The FL detector was set at $\lambda_{\mathrm{ex} / \mathrm{em}}, 225 / 310 \mathrm{~nm}$, to achieve optimum sensitivity.

Figure 1 shows the typical chromatograms for the separation of MFX and $p$ CPA mixture at retention times $3.81 \pm$ 0.06 and $9.82 \pm 0.08 \mathrm{~min}$, respectively using the proposed HPLCDAD-FL method.

System Suitability Parameters were assessed to ensure adequate performance of the chromatographic system. Retention time $\left(R_{t}\right)$, capacity factor $\left(k^{\prime}\right)$, number of theoretical plates $(N)$, peak resolution $\left(\mathrm{R}_{\mathrm{s}}\right)$, selectivity $(\alpha)$ and tailing factor $(\mathrm{T})$ were evaluated for six replicate injections of MFX and $p$ CPA standard solutions at concentrations of 20 and $8 \mu \mathrm{g} \mathrm{mL}^{-1}$, respectively. The results presented in Table1 are within the acceptable limits.
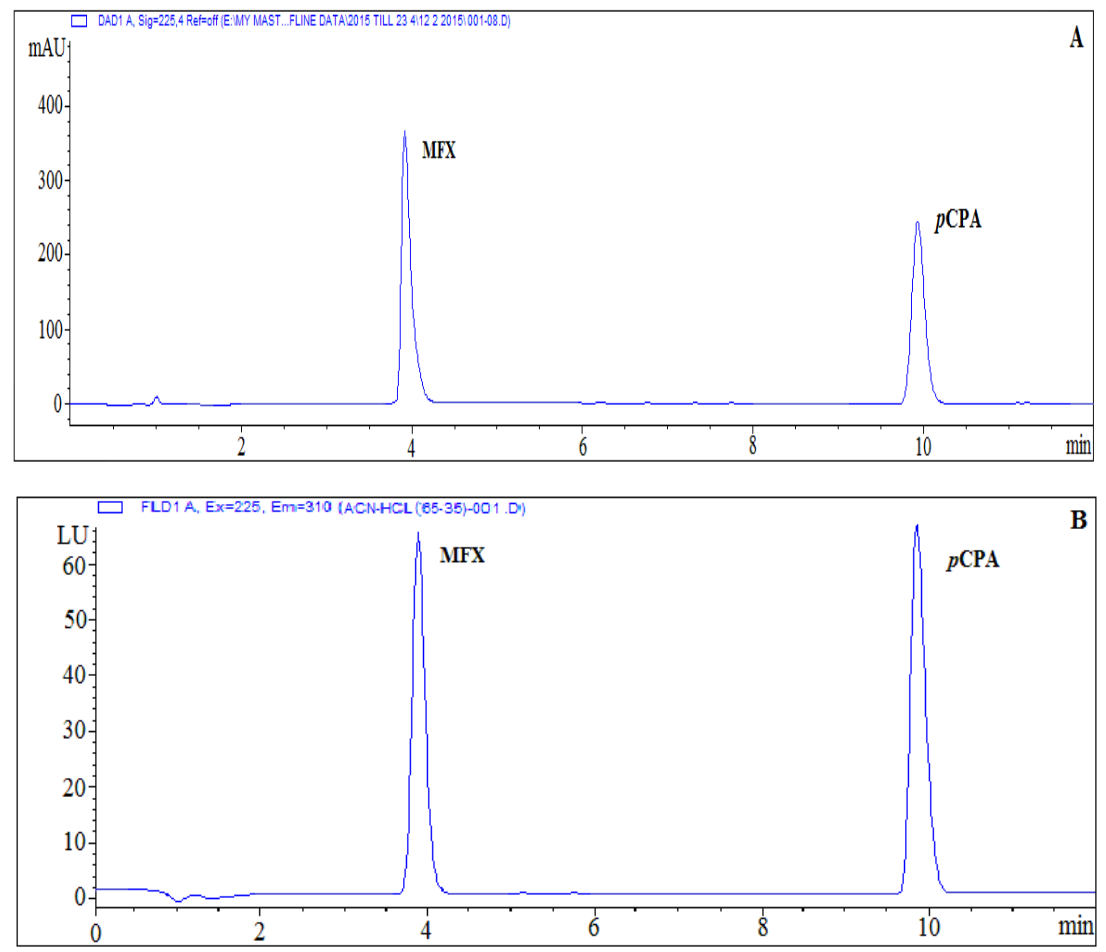

Fig. 1: HPLC chromatogram of $20-\mu \mathrm{L}$ injection of (A) a mixture containing $40 \mu \mathrm{g} \mathrm{mL}{ }^{-1} \mathrm{MFX}$ and $15 \mu \mathrm{g} \mathrm{mL}{ }^{-1} p \mathrm{CPA}$ using DAD at $225 \mathrm{~nm},(B)$ a mixture containing $5 \mu \mathrm{g} \mathrm{mL}^{-1} \mathrm{MFX}$ and $1 \mu \mathrm{g} \mathrm{mL}^{-1} p \mathrm{CPA}$ using FL at $\lambda_{\text {ex/em }}, 225 / 310 \mathrm{~nm}$.

Table 1: System suitability parameters ${ }^{\mathrm{a}}$ of the developed HPLC-DAD-FL method.

\begin{tabular}{|c|c|c|}
\hline Parameter & MFX & pCPA \\
\hline Retention time $(\min ) \mathrm{Rt} \pm \mathrm{SD}(\mathrm{n}=6)$ & $3.81 \pm 0.06$ & $9.82 \pm 0.08$ \\
\hline Capacity factor $\left(\mathrm{k}^{\prime}\right)$ & 2.81 & 8.82 \\
\hline Tailing factor $(\mathrm{T})$ & 1.11 & 1.13 \\
\hline Number of theoretical plates $(\mathrm{N})$ & 5806 & 16143 \\
\hline Selectivity $(\alpha)$ & & \\
\hline Resolution (Rs) & & \\
\hline
\end{tabular}

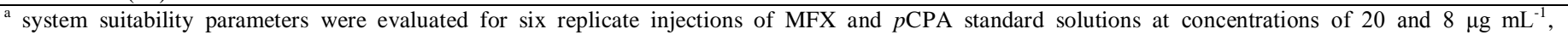
respectively, calculated as average of DAD and FL data. 


\section{Results from forced degradation studies}

The study aimed to evaluate the specificity of the method towards the separation of MFX from the potential degradation products. The hydrolytic degradation of MFX (in neutral, acidic and alkaline solutions) is well known and is a matter of many researches (Cooke et al., 1979; Tatsuhara and Tabuchi, 1980; Yoshioka et al., 1982; Yoshioka et al., 1983; Ohta et al., 1986; Araman et al., 1992; Otsuka et al., 1994; El-Bardicy et al., 2007 a; El-Bardicy et al., 2007b; El-Nashar et al., 2012). Table2 demonstrates the \% remaining of MFX, it is clear that the reaction is base-catalysed. The chromatograms (Figures 2- 4) show good resolution of MFX from the hydrolytic product, $p$ CPA. It should be noted that, N,N-dimethylamino ethanol is not detected as it is a non UV absorbing species.

Forced oxidative degradation was performed with $8 \%$ $\mathrm{H}_{2} \mathrm{O}_{2}$ for $24 \mathrm{~h}$ at ambient temperature and with $10 \% \mathrm{H}_{2} \mathrm{O}_{2}$ for $6 \mathrm{~h}$ at $80^{\circ} \mathrm{C}$. The DAD and FL chromatograms of the stressed samples showed peaks for MFX, $p \mathrm{CPA}$ and three oxidation products I, II, and III at 12.2, 14.60 and $15.80 \mathrm{~min}$, respectively, with good resolution of MFX and $p \mathrm{CPA}$ from the oxidation products (Figure 5). Analogus experiment was done on $p C P A$, HPLC analysis showed the same oxidation products I, II, and III at the same retention times (Figure 6). The stress oxidation reaction of MFX and $p$ CPA can be explained in the view of chromatographic results. MFX is highly liable to hydrolysis, even in $\mathrm{H}_{2} \mathrm{O}_{2}$ aqueous solution, which most probably occurs in preference to oxidation. The readiness of MFX to get oxidized is slow. Identical oxidation products in the chromatograms of MFX and $p$ CPA (as proved by retention times and UV spectra obtained by DAD) agreed with our assumption that these are the products of oxidation of $p$ CPA. This means that hydrolysis of MFX occurs first then followed by oxidation of the hydrolytic product. Only small fraction of $p \mathrm{CPA}$ gets oxidized, even with $10 \% \quad \mathrm{H}_{2} \mathrm{O}_{2}$ and heating for $6 \mathrm{~h}$ at $80^{\circ} \mathrm{C}$.This is in line with the reported oxidative degradation reaction of $p \mathrm{CPA}$ by $\mathrm{H}_{2} \mathrm{O}_{2}$ which has been catalized photochemically to force the reaction to completion (Lang and Lunák, 2002). The oxidation products are natively fluorescent species, detected in the FL chromatogram.

HPLC chromatograms of photo-degraded MFX (UV irradiated solid or solutions) showed only $p$ CPA peak, with no photo-degradation products. The hydrolysis of MFX was monitored in the \% remaining of MFX (Table 2).

In all stress degradation studies, the peak purity data for MFX and $p$ CPA were assessed (Table 2).
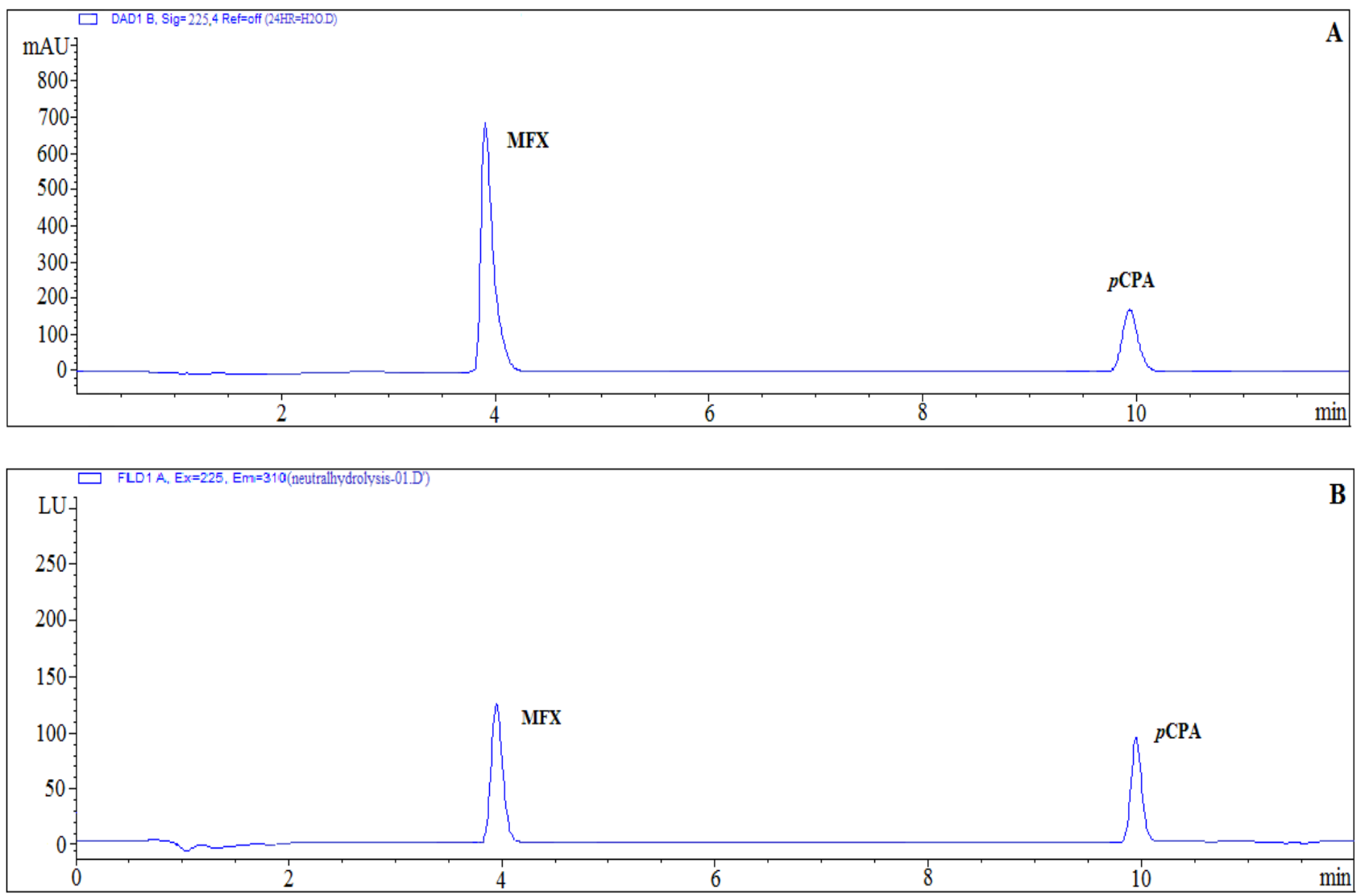

Fig. 2: HPLC Chromatogram of MFX after exposure to neutral hydrolysis for $6 \mathrm{hr}$ at ambient temperature (A) using DAD at $225 \mathrm{~nm}\left(100 \mu \mathrm{gg} \mathrm{mL}^{-1}\right.$, initial concentration), (B) using FLat $\lambda_{\mathrm{ex} / \mathrm{em}}, 225 / 310 \mathrm{~nm}\left(10 \mu \mathrm{g} \mathrm{mL} \mathrm{m}^{-1}\right.$, initial concentration). 
Table 2: Forced degradation studies.

\begin{tabular}{|c|c|c|c|c|}
\hline \multirow[b]{2}{*}{ Stress conditions } & \multicolumn{2}{|c|}{ \% remaining MFX } & \multirow{2}{*}{$\begin{array}{c}\text { DAD } \\
\text { Purity factor } \\
\text { MFX }\end{array}$} & \multirow{2}{*}{$\begin{array}{c}\text { DAD } \\
\text { purity factor } \\
p \text { CPA }\end{array}$} \\
\hline & DAD & FL & & \\
\hline Neutral hydrolysis, Distilled water, 6h, ambient temperature & 83.3 & 84.1 & 999.983 & 999.991 \\
\hline Acid hydrolysis, $0.1 \mathrm{M} \mathrm{HCl}, 6 \mathrm{~h}$, ambient temperature & 98.5 & 98.7 & 999.990 & 999.985 \\
\hline Base hydrolysis, $0.1 \mathrm{M} \mathrm{NaOH}, 5 \mathrm{~min}$, ambient temperature & 49.6 & 49.0 & 999.987 & 999.998 \\
\hline Oxidative degradation, $8 \% \mathrm{H}_{2} \mathrm{O}_{2}, 24 \mathrm{~h}$, ambient temperature & 51.3 & 52.4 & 999.992 & 1000 \\
\hline Oxidative degradation, $10 \% \mathrm{H}_{2} \mathrm{O}_{2}, 6 \mathrm{~h}, 80^{\circ} \mathrm{C}$ & 40.3 & 39.5 & 999.995 & 999.981 \\
\hline Photo-degradation, Solid drug, at $254 \mathrm{~nm}, 3 \mathrm{~h}$ & 99.6 & 99.4 & 999.984 & 999.997 \\
\hline Photo-degradation, Solution in $0.01 \mathrm{M} \mathrm{HCl}$, at $254 \mathrm{~nm}, 3 \mathrm{~h}$ & 98.7 & 98.6 & 999.989 & 999.983 \\
\hline Photo-degradation, Solution in distilled water, at $254 \mathrm{~nm}, 3 \mathrm{~h}$ & 90.6 & 91.1 & 999.997 & 999.992 \\
\hline
\end{tabular}
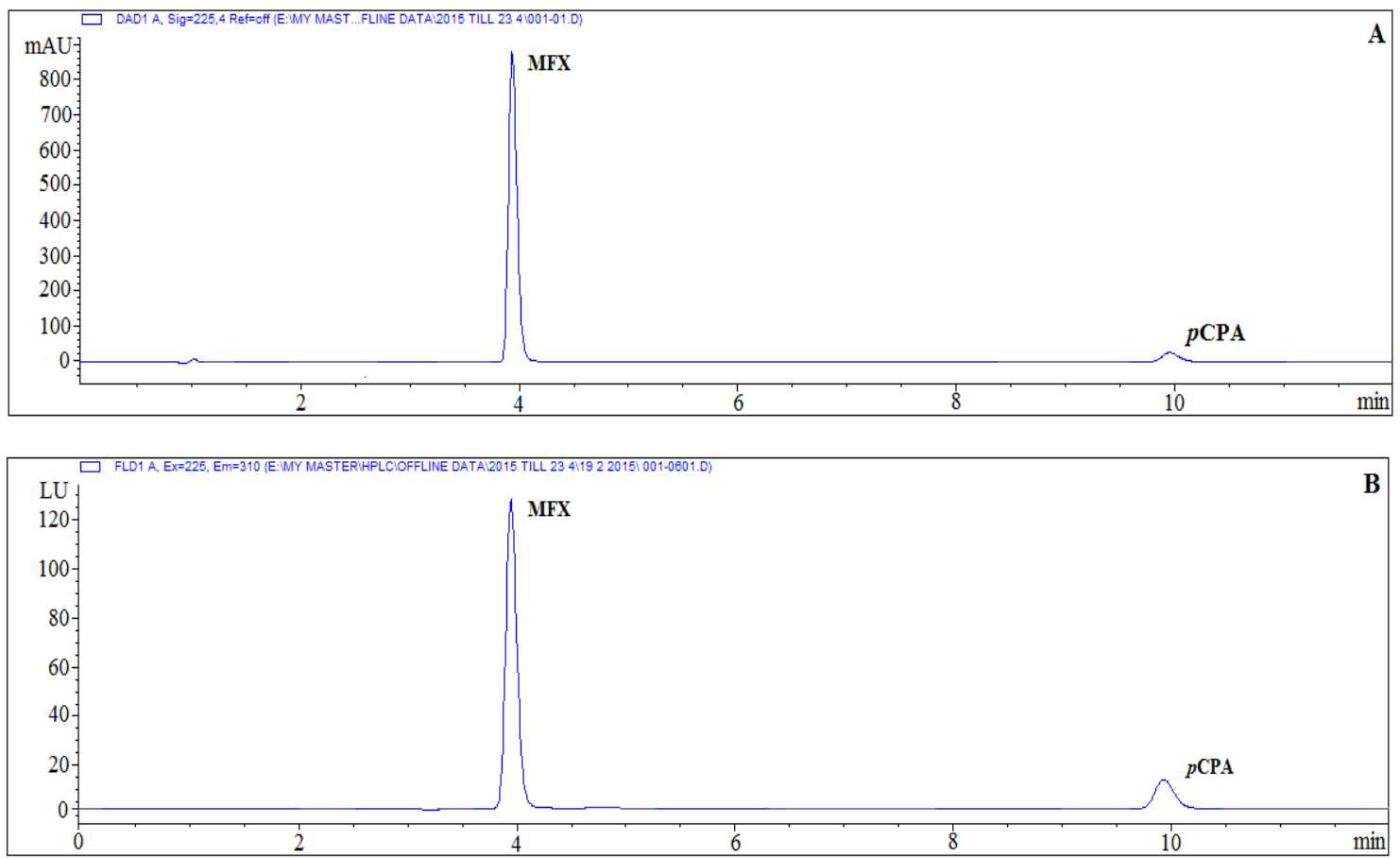

Fig. 3: HPLC Chromatogram of MFX after exposure to acid hydrolysis with $0.1 \mathrm{M} \mathrm{HCl}$ for $6 \mathrm{hr}$ at ambient temperature (A) using DAD at $225 \mathrm{~nm}\left(100 \mu \mathrm{g} \mathrm{mL}^{-1}\right.$, initial concentration), (B) using FLat $\lambda_{\text {ex/em }}, 225 / 310 \mathrm{~nm}\left(10 \mu \mathrm{g} \mathrm{mL}{ }^{-1}\right.$, initial concentration).
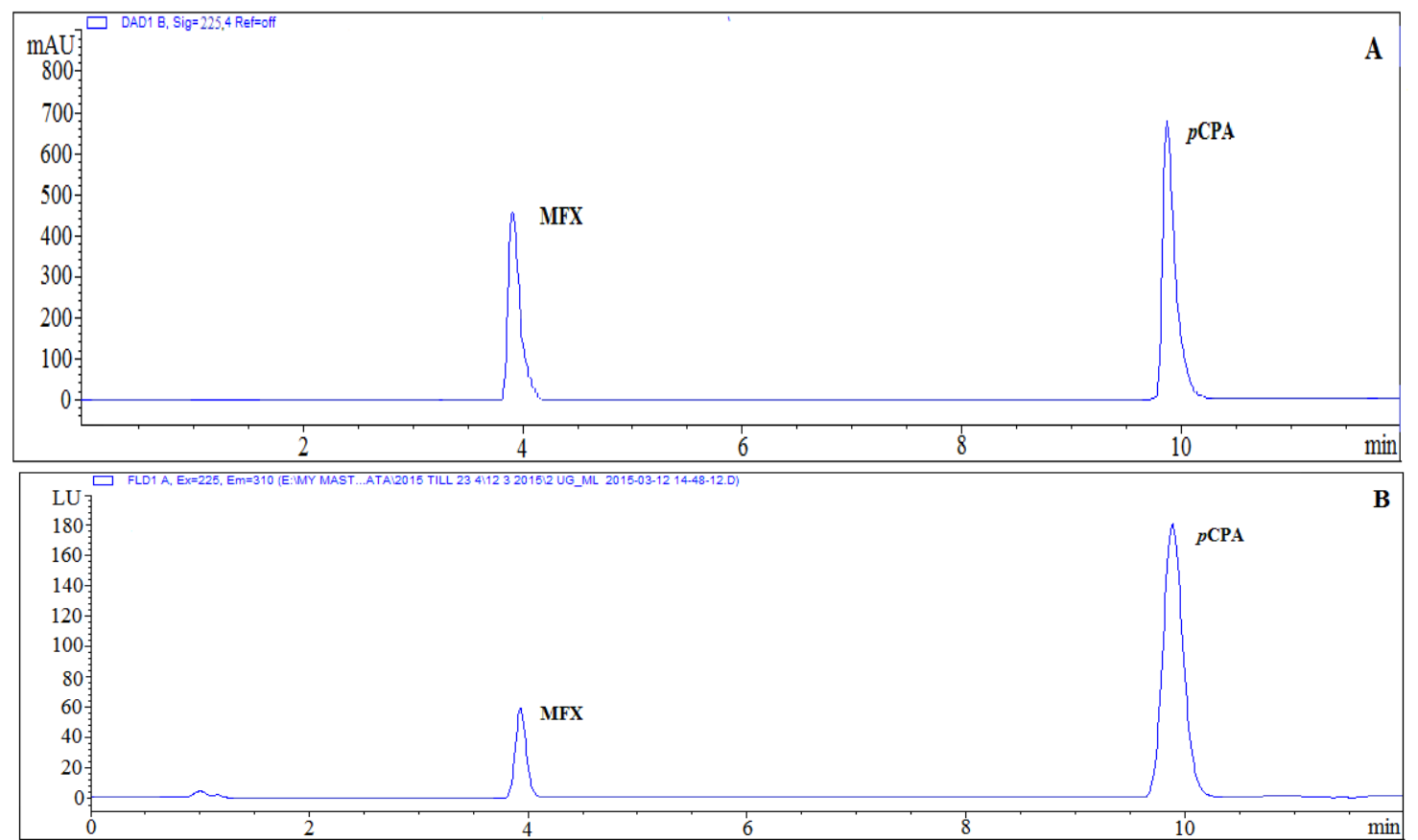

Fig. 4: HPLC Chromatogram of MFX after exposure to base hydrolysis with $0.1 \mathrm{M} \mathrm{NaOH}$ for $5 \mathrm{~min}$ at ambient temperature (A) using DAD at $225 \mathrm{~nm}$ (100 $\mu \mathrm{g}$ 

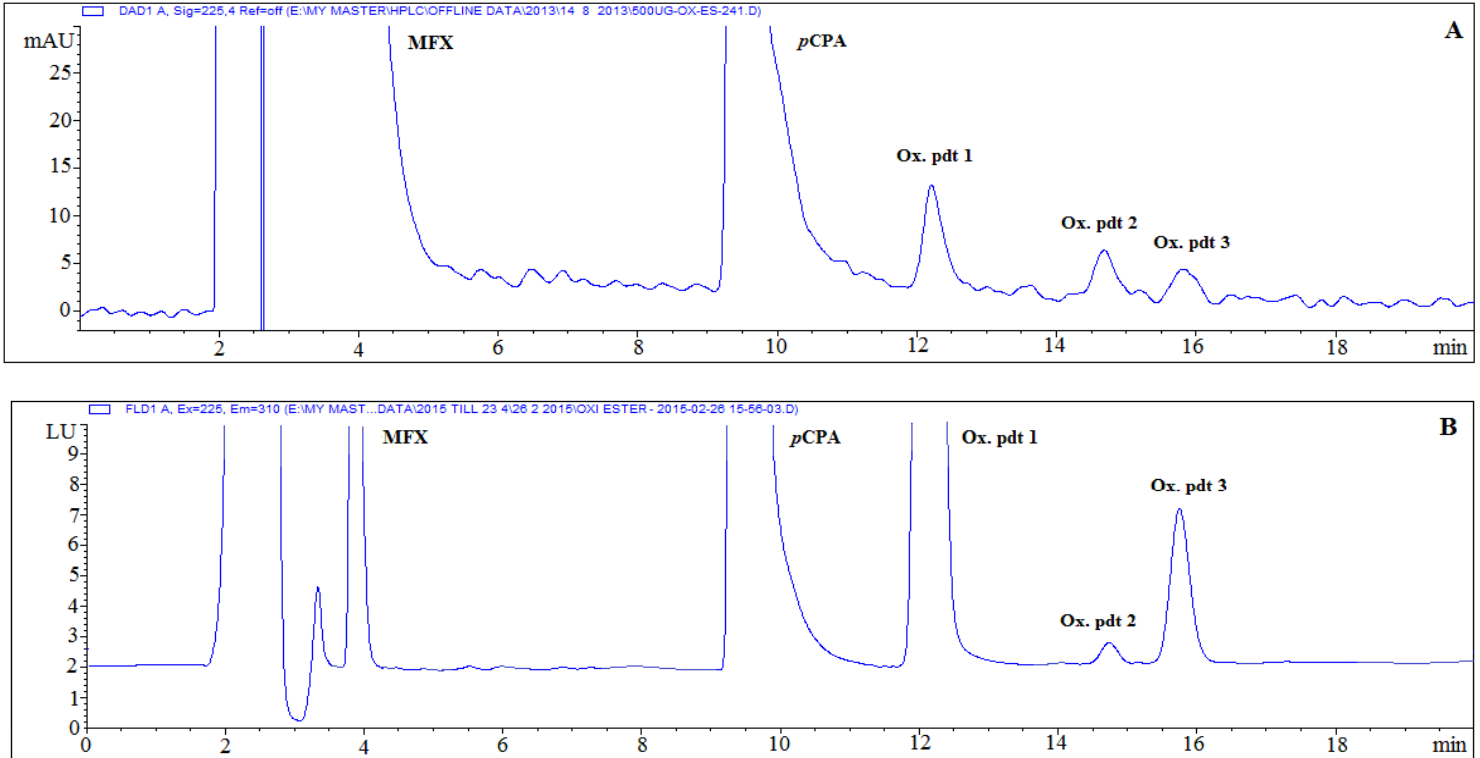

Fig. 5: HPLC chromatogram of $500 \mu \mathrm{g} \mathrm{ml}^{-1} \mathrm{MFX}$ after exposure to oxidative degradation with $8 \% \mathrm{H}_{2} \mathrm{O}_{2}$ for $24 \mathrm{~h}$ at ambient temperature (A) using DAD at 225 $\mathrm{nm}$, (B) using FL at $\lambda_{\text {ex/em }}, 225 / 310 \mathrm{~nm}$.
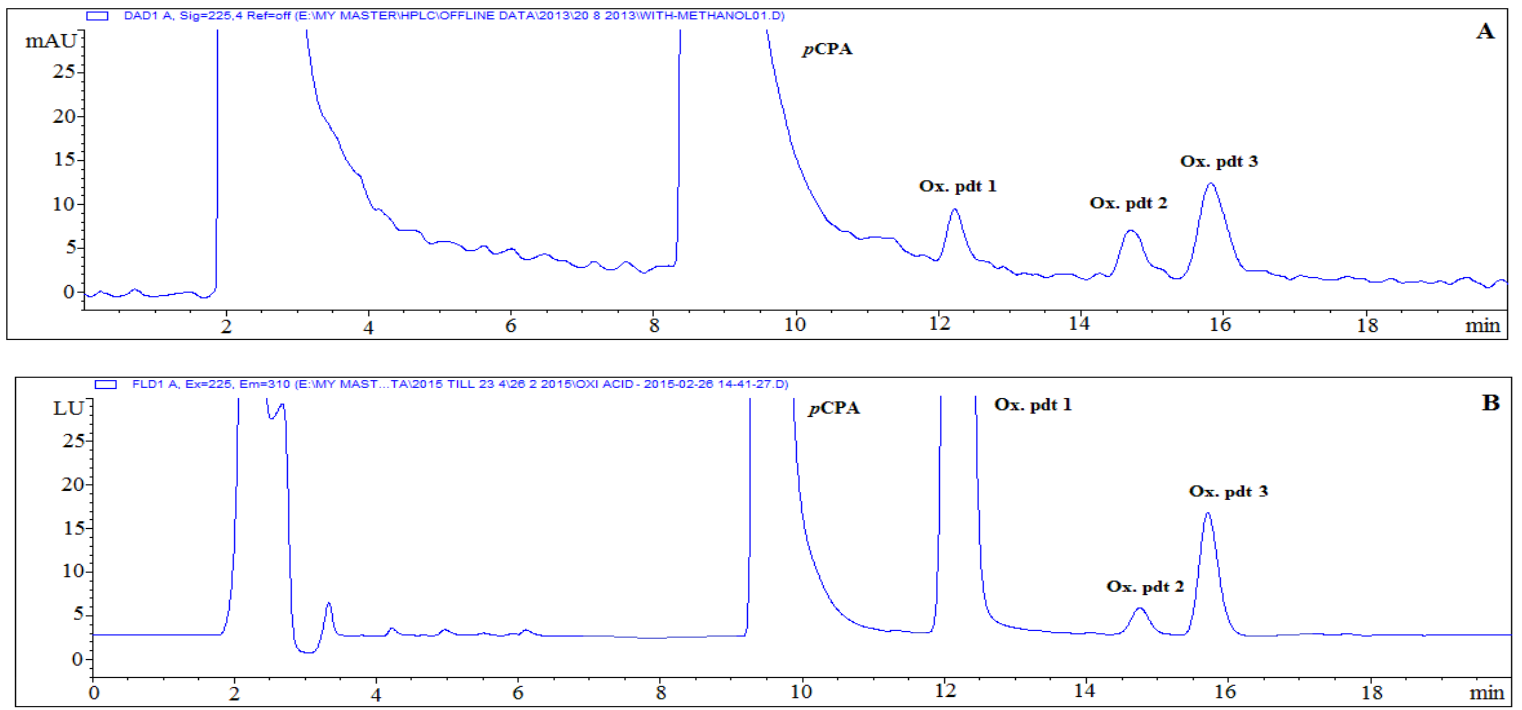

Fig. 6: HPLC chromatogram of $500 \mu \mathrm{gml}^{-1} p \mathrm{CPA}$ after exposure to oxidative degradation with $8 \% \mathrm{H}_{2} \mathrm{O}_{2}$ for $24 \mathrm{~h}$ at ambient temperature (A) using DAD at 225 $\mathrm{nm}$, (B) using FL at $\lambda_{\text {ex/em }}, 225 / 310 \mathrm{~nm}$.

Table 3: Analytical parameters for the determination of MFX and $p$ CPA using the proposed HPLC-DAD-FL method.

\begin{tabular}{|c|c|c|c|c|}
\hline \multirow[b]{2}{*}{ Parameters } & \multicolumn{2}{|c|}{ DAD } & \multicolumn{2}{|c|}{ FL } \\
\hline & MFX & $p$ CPA & MFX & $p$ CPA \\
\hline Wavelength $(\mathrm{nm})$ & 225 & 225 & $\lambda_{\text {ex/em }}=225 / 310$ & $\lambda_{\text {ex/em }}=225 / 310$ \\
\hline Linearity range $\left(\mu \mathrm{g} \mathrm{mL}^{-1}\right)$ & $0.5-100$ & $0.25-100$ & $0.05-20$ & $0.01-8$ \\
\hline Intercept (a) & -1.34 & 6.74 & -2.58 & 3.66 \\
\hline $\mathrm{S}_{\mathrm{a}}^{\mathrm{a}}$ & 2.09 & 6.51 & 3.28 & 4.20 \\
\hline Slope (b) & 50.01 & 96.10 & 62.64 & 321.82 \\
\hline $\mathrm{S}_{\mathrm{b}}{ }^{\mathrm{T}}$ & 0.05 & 0.73 & 0.37 & 1.30 \\
\hline $\mathrm{RSD} \%$ of the slope $\left(\mathrm{S}_{\mathrm{b}} \%\right)$ & 0.10 & 0.76 & 0.59 & 0.40 \\
\hline Correlation coefficient (r) & 0.99999 & 0.99990 & 0.99991 & 0.99994 \\
\hline $\mathrm{S}_{\mathrm{y} / \mathrm{x}}{ }^{\mathrm{c}}$ & 4.09 & 12.08 & 8.15 & 10.33 \\
\hline $\operatorname{LOD}^{\mathrm{d}}\left(\mu \mathrm{g} \mathrm{mL}^{-1}\right)$ & 0.05 & 0.04 & 0.005 & 0.001 \\
\hline $\mathrm{LOQ}^{\mathrm{e}}\left(\mu \mathrm{g} \mathrm{mL}^{-1}\right)$ & 0.16 & 0.13 & 0.018 & 0.005 \\
\hline
\end{tabular}




\section{Validation of the proposed method}

\section{Linearity and concentration ranges}

Standard solutions of six concentration levels, for MFX and $p$ CPA, were prepared and injected twice for each level onto the HPLC system. Table 3 presents the linearity data and statistical parameters including concentration ranges, slope (b) and intercept (a) of the linear regression equations, correlation coefficients and standard deviations of the intercept $\left(\mathrm{S}_{\mathrm{a}}\right)$, slope $\left(\mathrm{S}_{\mathrm{b}}\right)$ and residuals $\left(\mathrm{S}_{\mathrm{y} / \mathrm{x}}\right)$. Regression analysis for the calibration curves showed good linear relationship over the concentration ranges stated in the table as judged by the correlation coefficient values ( $r>0.9999)$ and RSD\% of the slope $\left(\mathrm{S}_{\mathrm{b}} \%\right)$ which did not exceed $0.76 \%$.

\section{Limits of detection and quantitation}

The limit of detection (LOD) and limit of quantitation (LOQ) were calculated in accordance to the USP and ICH guidelines based on signal-to-noise ratio values(ICH, 2005). Data given in Table 3 reveals that the proposed method is sensitive enough to detect concentrations down to 0.05 and $0.04 \mu \mathrm{gL}^{-1}$ (DAD); and 0.005 and $0.001 \mu \mathrm{g} \mathrm{mL}^{-1}$ (FL) for MFX and $p$ CPA, respectively.

\section{Accuracy}

Accuracy of the developed methods was determined by performing recovery experiments. Known amounts of standards MFX and $p C P A$ at three concentration levels were fortified to preanalysed degraded samples (MFX sample at $20 \mu \mathrm{g} \mathrm{mL} \mathrm{m}^{-1}$ concentration level was exposed to oxidative degradation using $10 \% \mathrm{H}_{2} \mathrm{O}_{2}$ at $80^{\circ} \mathrm{C}$ for $6 \mathrm{~h}$, pre-analysed results were $8.05 \mu \mathrm{g} \mathrm{mL}^{-1}$ MFX and $\left.5.06 \mu \mathrm{g} \mathrm{mL} \mathrm{m}^{-1} \mathrm{CPA}\right)$. Three replicate samples of each concentration level were prepared and the percentage recovery at each level was determined (Table4), taking into consideration that the peak area of the standard added was calculated by the difference in peak area between fortified and unfortified samples. The mean percentage recoveries obtained ranged from 98.2 to $101.6 \%$. The percentage relative standard deviation (RSD\%) did not exceed $1.5 \%$.

Table 4: Accuracy of the proposed HPLC-DAD-FL method.

\begin{tabular}{|c|c|c|c|}
\hline \multirow{2}{*}{$\begin{array}{c}\text { Amount of } \\
\text { standard MFX }^{\text {Mandified }} \\
\text { fortified }^{\mathrm{a}} \\
\mu \mathrm{g} \mathrm{mL}^{-1}\end{array}$} & \multirow{2}{*}{$\begin{array}{c}\text { Amount of } \\
\text { standard } p \text { CPA } \\
\text { fortified }^{\mathrm{a}} \\
\mu \mathrm{g} \mathrm{mL}^{-1}\end{array}$} & \multicolumn{2}{|c|}{$\begin{array}{c}\text { Mean \% } \\
\text { recovery }{ }^{\mathrm{b}} \pm \mathrm{SD}^{\mathrm{c}} \text { of } \\
\text { fortified }\end{array}$} \\
\hline & & MFX & $p$ CPA \\
\hline \multicolumn{4}{|l|}{ DAD } \\
\hline 1 & 1 & $98.3 \pm 0.62$ & $101.0 \pm 0.91$ \\
\hline 20 & 20 & $101.6 \pm 0.89$ & $100.4 \pm 0.78$ \\
\hline 40 & 40 & $99.6 \pm 1.10$ & $98.9 \pm 1.3$ \\
\hline \multicolumn{4}{|l|}{ FL } \\
\hline 0.5 & 0.02 & $100.7 \pm 0.59$ & $99.2 \pm 0.81$ \\
\hline 5 & 1.0 & $99.9 \pm 1.42$ & $100.9 \pm 0.97$ \\
\hline 10 & 2.0 & $101.3 \pm 0.75$ & $98.2 \pm 1.50$ \\
\hline
\end{tabular}

${ }^{a}$ standards fortified to pre-analysed degraded samples containing $8.05 \mu \mathrm{g} \mathrm{mL}^{-1}$ MFX and $5.06 \mu \mathrm{g} \mathrm{mL}{ }^{-1} p$ CPA. ${ }^{b}$ recovery obtained by difference in peak area between fortified and unfortified pre-analysed degraded samples. ${ }^{\mathrm{c}}$ standard deviation $(n=3)$.

\section{Precision}

Intra-day and inter-day precision were evaluated by analyzing three replicates over three concentration levels of standards MFX and $p$ CPA, within the same day (intra-day repeatability) and on three consecutive days (inter-day precision). The intra-day and inter-day precision (\% RSD) was found to be less than $2 \%$ (Table5), indicating that the method is precise.

Table 5: Intra-day and inter-day precision of the proposed HPLC-DAD-FL method.

\begin{tabular}{|c|c|c|c|}
\hline Analyte & $\begin{array}{c}\text { Conc } \\
\mu \mathrm{g} \mathrm{mL} L^{-1}\end{array}$ & $\begin{array}{c}\text { Intra-day } \\
\text { RSD }^{\mathrm{a}}\end{array}$ & $\begin{array}{c}\text { Inter-day } \\
\text { RSD }^{\mathrm{a}}\end{array}$ \\
\hline \multicolumn{4}{|l|}{ DAD } \\
\hline \multirow{3}{*}{ MFX } & 0.5 & 0.61 & 0.98 \\
\hline & 40 & 1.23 & 1.47 \\
\hline & 100 & 0.90 & 1.75 \\
\hline \multirow{3}{*}{$p \mathrm{CPA}$} & 0.25 & 0.76 & 0.90 \\
\hline & 40 & 0.81 & 0.99 \\
\hline & 100 & 1.01 & 1.23 \\
\hline \multicolumn{4}{|l|}{$\overline{\text { FL }}$} \\
\hline \multirow{3}{*}{ MFX } & 0.05 & 1.12 & 1.34 \\
\hline & 10 & 0.79 & 0.82 \\
\hline & 20 & 0.63 & 0.93 \\
\hline \multirow{3}{*}{$p \mathrm{CPA}$} & 0.01 & 0.96 & 1.45 \\
\hline & 4 & 1.58 & 1.76 \\
\hline & 8 & 0.84 & 1.19 \\
\hline
\end{tabular}

\section{Specificity}

The specificity of the developed HPLC-DAD-FL method was demonstrated by its ability to measure accurately and specifically MFX and $p$ CPA in the presence of other potential degradants or excipients (ICH, 2005).

Photodiode array detector was used to evaluate the homogeneity and purity of the chromatographic peaks. Chromatographic peak purity data was obtained from the Agilent Chemstation Software (Stahl, 2003).A similarity factor of 0 indicates no match and that of 1000 indicates identical spectra. Generally, values very close to the ideal similarity factor (greater than 995) indicate that the spectra are very similar (Stahl, 2003). The similarity factors for, MFX and $p$ CPA peaks in the chromatograms of stressed samples, assayed tablets and vials were found to be in the range of 999.983-1000. All these factors lie within the corresponding automatically computed noise threshold limits indicating pure peaks. The threshold limits were found to be in the range of 999.936-999.974.

The specificity of the HPLC methods is also illustrated from chromatograms obtained with the mixture solution of standard MFX/pCPA, stressed samples, tablets solution and vials solution. Well-resolved peaks were observed for MFX and $p \mathrm{CPA}$ in all the studied chromatograms( $\mathrm{Rs}=16.61)$, and for $p \mathrm{CPA}$ and oxidation product $\mathrm{I}$ in the stressed samples chromatograms (Rs =3.85). Additionally, either of MFX or pCPA showed identical retention times in all the studied chromatograms. No interfering peaks from any of the excipients appear in tablets chromatogram.

Method specificity was further confirmed by the recovery experiments carried out on standards MFX and $p \mathrm{CPA}$ added to degraded samples (Table 4). This indicates that the 
Table 6: Assay results of MFX and $p$ CPA in commercial pharmaceutical preparations using the proposed HPLC-DAD-FL method.

\begin{tabular}{|c|c|c|c|c|c|c|c|c|}
\hline \multirow{3}{*}{ Batch number } & \multicolumn{4}{|c|}{ Found MFX ${ }^{\mathrm{a}}$} & \multicolumn{4}{|c|}{ Found $p \mathrm{CPA}^{\mathrm{a}}$} \\
\hline & \multicolumn{2}{|c|}{ DAD } & \multicolumn{2}{|c|}{ FL } & \multicolumn{2}{|c|}{ DAD } & \multicolumn{2}{|c|}{ FL } \\
\hline & Mean\% & RSD\% & Mean\% & RSD \% & $\begin{array}{c}\text { Mean } \\
\text { mg/tablet }\end{array}$ & RSD\% & $\begin{array}{c}\text { Mean } \\
\text { mg /tablet }\end{array}$ & RSD \% \\
\hline \multicolumn{9}{|l|}{ Lucidril $^{\circledR}$ tablets } \\
\hline CEE1662 & 96.5 & 0.96 & 96.6 & 0.76 & 5.69 & 0.85 & 5.53 & 0.97 \\
\hline EEE1518 & 96.6 & 0.72 & 96.4 & 1.20 & 5.54 & 0.79 & 5.85 & 0.60 \\
\hline DAE0153 & 95.9 & 1.18 & 96.0 & 0.67 & 6.66 & 1.16 & 6.50 & 1.00 \\
\hline \multicolumn{9}{|l|}{ Lucifort $^{\circledR}$ vials } \\
\hline DDE1158 & 96.7 & 0.72 & 96.8 & 0.73 & 10.73 & 0.84 & 10.40 & 1.16 \\
\hline DAE0057 & 96.6 & 0.83 & 96.6 & 0.77 & 11.05 & 0.83 & 11.05 & 0.87 \\
\hline CDE1089 & 96.4 & 0.79 & 96.3 & 0.62 & 11.70 & 0.99 & 12.03 & 0.78 \\
\hline
\end{tabular}

${ }^{a}$ mean of five replicates.

developed method was specific and can be applied to simultaneous estimation of MFX and $p$ CPA in kinetic stability study of MFX and in analysis of pharmaceutical formulations, to monitor the $\%$ degraded.

\section{Stability of Solutions}

Standard solution of MFX, prepared in $0.1 \mathrm{M} \mathrm{HCl}$, is stable at ambient temperature for up to8h only (regarding the $t_{98 \%}$, time required for the drug concentration to fall to $98 \%$ of the original value), so it should be freshly prepared daily. Standard solution of $p$ CPA prepared in methanol/water is stable and can be kept in refrigerator for about one week. The stability was verified by chromatographic analysis and monitoring the respective retention time and peak area.

\section{Robustness}

To evaluate the robustness of the developed HPLCDAD-FL method, small deliberate variations in optimized methods parameters were made once at a time (ICH, 2005). The parameters included variation of flow rate $\left( \pm 0.05 \mathrm{~mL} \mathrm{~min}^{-1}\right)$,detection wavelengths $( \pm 1 \mathrm{~nm}), \mathrm{pH}$ of the phosphate buffer $( \pm 0.05)$, and $\%$ of acetonitrile in the mobile phase $( \pm 0.5 \%)$. Replicate injections $(\mathrm{n}=3)$ of standard solutions $\left(40 \mu \mathrm{g} \mathrm{mL}^{-1} \mathrm{MFX}\right.$ and $15 \mu \mathrm{g} \mathrm{mL} \mathrm{LCPA}^{-1} \mathrm{CPA}$ for DAD) (5 $\mathrm{g} \mathrm{mL}^{-1} \mathrm{MFX}$ and $1 \mu \mathrm{g} \mathrm{mL}^{-1} p \mathrm{CPA}$ for FL) were used. These variations have no significant effect on the peak area, retention time, tailing factor and resolution of the analytes.

\section{Applications of the developed method}

\section{Assay of MFX Tablet and Vial dosage forms}

The developed HPLC-DAD-FL method was applied to the assay of MFXcommercial pharmaceutical formulations (Lucidril $^{\circledR}$ tablets and Lucifort ${ }^{\circledR}$ vials).Both the intact drug and its hydrolytic degradation product, $p \mathrm{CPA}$ were determined in 3 different batches. It should be noted that the samples were extracted with methanol prior to $0.01 \mathrm{M} \mathrm{HCL}$ to dissolve any present $p$ CPA. The stability of MFX in methanol/ $\mathrm{HCl}$ was proved in the current kinetic study.In all batches, the mean $\%$ of MFX found was in the range of $95.9-96.8 \%$ and for $p C P A$, the mean amount found was in the range of $5.53-6.66 \mathrm{mg}$ per tablet and $10.40-12.03 \mathrm{mg}$ per vial (Table 6). The hydrolysis of MFX in commercial dosage forms is attributed to heat and humidity of storage conditions. The results agreed with the reported study on the hydrolysis of MFX in commercial tablets (Yoshioka et al., 1983).

\section{Kinetic stability studies of MFX}

Hydrolysis of MFX, in aqueous solution, is known to be first order reaction and $\mathrm{pH}$ dependent (Ohta et al., 1986). Some kinetic studies on MFX stability have been reported. These include MFX stability in solid dosage form to investigate effect of temperature and humidity (Yoshioka et al., 1982; Yoshioka et al., 1983), hydrolysis of MFX in buffer solutions at $\mathrm{pH} 4$ to 11 (Cooke et al., 1979)and degradation reaction of MFX in 1M, 1.5M and 2M $\mathrm{NaOH}$ (El-Bardicy et al., 2007 a).

In the present work, the kinetic studies on MFX stability aimed to serve drug analysis, in view of selecting the most appropriate solvents to prepare stable MFX solutions or even optimization of the analytical method conditions (like $\mathrm{pH}$ of the solution, \% organic solvent) to compromise drug stability and method sensitivity. So, the current kinetic study included stability of MFX in aqueous solutions of different $\mathrm{pH}$ values and in aqueous/organic solvent mixtures, as summarized in Table 7 . The developed HPLC-DAD-FL method was applied to monitor the percentage remaining of MFX in the investigated media. The kinetic parameters were calculated using equations (1) and (2) (Sinko, 2006):

$$
\begin{aligned}
& \log \mathrm{C}_{\mathrm{t}} / \mathrm{C}_{0}=-\mathrm{k} / 2.303 \mathrm{t} \\
& \mathrm{t}_{1 / 2}=0.693 / \mathrm{k}
\end{aligned}
$$

where, $\mathrm{k}$ is the first order reaction rate constant, $\mathrm{C}_{0}$ is the concentration of MFX at time $t=0$ and $C_{t}$ is its concentration at time $\mathrm{t}$. The degradation reaction rate constant was calculated from the slope of regression line representing the correlation of $\log \%$ remaining of MFX and time. The kinetic parameters, presented in Table 7, include: $\mathrm{k}$ (rate constant), $\mathrm{t}_{1 / 2}$ (half-life time) and $\mathrm{t}_{90 \%}$ (time required for the drug concentration to fall to $90 \%$ of the original value).

From the data given in Table 7, our findings could be reviewed in the following remarks: first, MFX is not stable enough 
Table 7: Kinetic parameters of MFX in different media using the proposed HPLC-DAD-FL method.

\begin{tabular}{|c|c|c|c|c|c|c|}
\hline \multirow{3}{*}{ Media } & \multirow{2}{*}{\multicolumn{2}{|c|}{$\begin{array}{c}\mathbf{K} \\
\left(\mathrm{min}^{-1}\right)^{\mathbf{a}}\end{array}$}} & \multicolumn{4}{|c|}{$t(\min )^{b}$} \\
\hline & & & \multicolumn{2}{|c|}{$\mathbf{t}_{1 / 2}$} & \multicolumn{2}{|c|}{$\mathbf{t}_{\mathbf{9 0} \%}$} \\
\hline & DAD & FL & DAD & FL & DAD & FL \\
\hline $0.1 \mathrm{M} \mathrm{NaOH}$ & $14 \times 10^{-2}$ & $15 \times 10^{-2}$ & 4.95 & 4.62 & 0.75 & 0.70 \\
\hline Ammonium carbonate: acetonitrile (70: 30) pH 8.6 & $96 \times 10^{-3}$ & $99 \times 10^{-3}$ & 7.2 & 7.0 & 1.1 & 1.1 \\
\hline Methanol: phosphate buffer pH $7.4(1: 1)$ & $61 \times 10^{-3}$ & $62 \times 10^{-3}$ & 11.4 & 11.2 & 1.7 & 1.7 \\
\hline $20 \mathrm{mM}$ phosphate buffer $\mathrm{pH} 7.4$ & $48 \times 10^{-3}$ & $44 \times 10^{-3}$ & 14.4 & 15.75 & 2.2 & 2.4 \\
\hline Buffer for reconstitution of vial $^{c}$ & $19 \times 10^{-3}$ & $18 \times 10^{-3}$ & 36.5 & 38.5 & 5.5 & 5.8 \\
\hline Methanol: water $(1: 1)$ & $59 \times 10^{-4}$ & $55 \times 10^{-4}$ & 117.5 & 126.0 & 17.8 & 19.1 \\
\hline Methanol & $33 \times 10^{-4}$ & $35 \times 10^{-4}$ & 210.0 & 198.0 & 31.8 & 30.0 \\
\hline Distilled water & $51 \times 10^{-5}$ & $48 \times 10^{-5}$ & 1358.8 & 1443.8 & 206.6 & 218.8 \\
\hline Methanol: $\mathrm{HCl} 0.1 \mathrm{M}(1: 1)$ & $21 \times 10^{-5}$ & $20 \times 10^{-5}$ & 3300 & 3465.0 & 500 & 526.9 \\
\hline Methanol : $20 \mathrm{mM}$ acetate buffer $\mathrm{pH} 3(1: 1, \mathrm{v} / \mathrm{v})$ & $17 \times 10^{-5}$ & $19 \times 10^{-5}$ & 4076.5 & 3647.4 & 617.6 & 554.6 \\
\hline Normal saline & $17 \times 10^{-5}$ & $18 \times 10^{-5}$ & 4076.5 & 3850.0 & 617.6 & 585.4 \\
\hline $20 \mathrm{mM}$ acetate buffer $\mathrm{pH} 3$ & $73 \times 10^{-6}$ & $70 \times 10^{-6}$ & 9493.2 & 9900.0 & 1438.4 & 1505.4 \\
\hline Acetonitrile : $20 \mathrm{mM}$ phosphate buffer $\mathrm{pH} 3(35: 65, \mathrm{v} / \mathrm{v})$ & $71 \times 10^{-6}$ & $69 \times 10^{-6}$ & 9760.6 & 10043.5 & 1484.2 & 1527.2 \\
\hline $0.1 \mathrm{M} \mathrm{HCl}$ & $42 \times 10^{-6}$ & $40 \times 10^{-6}$ & 16500 & 17325 & 2509.0 & 2634.5 \\
\hline $0.01 \mathrm{M} \mathrm{H}_{2} \mathrm{SO}_{4}$ & $35 \times 10^{-6}$ & $36 \times 10^{-6}$ & 19800 & 19250 & 3010.9 & 2927.2 \\
\hline
\end{tabular}

${ }^{\mathrm{a}}$ rate constant.

${ }^{b} t$, time required for MFX to fall to $50 \%\left(\mathrm{t}_{1 / 2}\right)$ and $90 \%\left(\mathrm{t}_{90 \%}\right)$ of the original value.

${ }^{c}$ composed of $18.06 \mathrm{mg}$ disodium phosphate and $17.61 \mathrm{mg}$ potassium dihydrogen o-phosphate ,pH 6.82 .

Table 8: Dissolution study of Lucidril ${ }^{\circledR}$ tablets using the proposed HPLC-DAD-FL method.

\begin{tabular}{|c|c|c|c|c|}
\hline \multirow{3}{*}{ Time (min) } & \multicolumn{4}{|c|}{ Average MFX dissolved $^{\mathrm{a}}$} \\
\hline & \multicolumn{2}{|c|}{ DAD } & \multicolumn{2}{|c|}{ FL } \\
\hline & mg & $\%$ & mg & $\%$ \\
\hline 5 & 43.3 & 17.3 & 44.0 & 17.6 \\
\hline 10 & 106.0 & 42.4 & 108.0 & 43.2 \\
\hline 15 & 137.0 & 54.8 & 134.0 & 53.6 \\
\hline 20 & 191.5 & 76.5 & 194.0 & 77.6 \\
\hline 25 & 213.3 & 85.3 & 215.8 & 86.3 \\
\hline 30 & 218.5 & 87.4 & 219.3 & 87.7 \\
\hline 40 & 224.8 & 89.9 & 226.5 & 90.6 \\
\hline 50 & 229.3 & 91.7 & 231.0 & 92.4 \\
\hline 60 & 233.5 & 93.4 & 234.5 & 93.8 \\
\hline
\end{tabular}

${ }^{\mathrm{a}}$ The dissolution data were obtained by averaging three parallel studies.

in water, its $\mathrm{t}_{90 \%} \approx 210 \mathrm{~min}$, alsoMFX in methanol, its $\mathrm{t}_{90 \%} \approx 31$ min, so either water or methanol is not suitable for preparation of standard MFX solution. Second, $t_{1 / 2}$ of MFX in ammonium carbonate: acetonitrile (70: 30$)$ of $\mathrm{pH} 8.6 \approx 7 \mathrm{~min}$, so it is not suitable to be used as mobile phase.Third, $t_{1 / 2}$ of MFX in $0.1 \mathrm{M}$ $\mathrm{NaOH}$ is $<5$ min; this is in agreement with that in reference (Cooke et al., 1979) and it seems to be more realistic than the kinetic data given for MFX hydrolysis in $\mathrm{NaOH}$, in reference (ElBardicy et al., 2007 a).

As a conclusion, some points, seem to be valuable and should be high-lighten. First, MFX exhibits best stability in aqueous acidic solution of $\mathrm{pH} 1-3\left(\mathrm{HCl}, \mathrm{H}_{2} \mathrm{SO}_{4}\right.$ and acetate buffer). Second, methanol fastens the degradation reaction, as seen in mixtures of methanol with water, $\mathrm{HCl}$, and buffers of $\mathrm{pH} 3$ and 7.4. However, acetonitrile and methanol added to acidic aqueous solutions, still keep good stability required for performing analytical experiments.

\section{In vitro dissolution study of tablet dosage form}

The developed HPLC-DAD-FL method was applied to calculate the amount of MFX released from Lucidril ${ }^{\circledR}$ tablets (Table 8). The results showed that more than $75 \%$ of the drug dissolved within 20 min and about $93 \%$ of the labeled MFX per tablet eventually dissolved in $60 \mathrm{~min}$. The dissolution profile for tablets was considered satisfactory and agreed with the results reported for lucidril ${ }^{\circledR}$ tablets, manufactured by Minapharm, Egypt (El-Nashar et al., 2012).

\section{CONCLUSION}

The present work described a simple, sensitive and reliable HPLC-DAD-FL method for the assay of MFX and $p$ CPA. The paper is the first to exploit the native fluorescence properties of MFX and its hydrolytic product, $p \mathrm{CPA}$, to establish a sensitive HPLC method. The limits of quantitation were found to be 18 and $5 \mathrm{ngmL}^{-1}$ for MFX and $p$ CPA, respectively with fluorescence detection without any derivatization.

The developed method is superior to the other previously reported analytical methods, as the present work considered hydrolytic, oxidative and photolytic degradations. To our knowledge, the previous attempts have concerned only with hydrolytic degradation. The developed HPLC-DAD-FL method was successfully applied to the analysis of MFX tablets and vials, to determine the intact drug as well as the hydrolytic product, $p C P A$, also applied to the dissolution testing of MFX tablets. Further, the method was applied to kinetic studies on MFX hydrolytic degradation reaction. Kinetic parameters including degradation rate constant, $t_{1 / 2}$ and $t_{90 \%}$ were estimated. The kinetic 
data are especially valuable to give attention about the most appropriate media, which favor MFX stability, to be a guide in establishing analytical method conditions.

\section{REFERENCES}

Almansa Lopez EM, Garcia-Campana AM, Aaron JJ, Cuadros Rodriguez L. Simultaneous quantification of chlorophenoxyacid herbicides based on time-resolved photochemical derivatization to induce fluorescence in micellar medium. Talanta, 2003; 60: 355-367.

Araman A, Caybasi P, Guven KC.Stability of Meclofenoxate Hydrochloride in artificial gastric and intestinal media. Pharmazie, 1992; 47: 147.

Cecal Al,Oniscu C,Horoba E.Radiochemical determination of meclofenoxate in different solutions. Pharmazie, 1983; 38: 562.

Cooke W, Zuckerman B, Howard Schneider F. Hydrolysis of centrophenoxine in culture media: Analysis by high pressure liquid chromatography. Age, 1979; 2: 13-16.

El-Bardicy MG, Lotfy HM,El-SayedMA,El-Tarras MF. Kinetic study on the degradation of meclophenoxate hydrochloride in alkaline aqueous solutions by high performance liquid chromatography. Yakugaku Zasshi, 2007 a; 127: 193- 199.

El-Bardicy MG,Lotfy HM,El-Sayed MA,El-Tarras MF.Stability indicating electrochemical methods for the determination of meclophenoxate hydrochloride and pyritinol dihydrochloride using ionselective membrane electrodes. Yakugaku Zasshi, 2007 b; 127:201-208.

El-Nashar RM,Abdel Ghani NT,Hassan SM.Construction and performance characteristics of new ion selective electrodes based on carbon nanotubes for determination of meclofenoxate hydrochloride. Analytica Chimica Acta, 2012; 730:99-111.

Eremin SA, Laassis B, Aaron JJ. Photochemical-fluorimetric method for the determination of total chlorophenoxyacid herbicides. Talanta, 1996; 43:295-301.

Fecko J.Spectrophotometric determination of 4chlorophenoxyacetic acid dimethylaminoethyl ester hydrochloride. Acta Poloniae Pharmaceutica - Drug Research, 1973; 30: 61-65.

Garcia LF, EreminS, Aaron JJ. Flow-Injection Analysis of Chlorophenoxyacid Herbicides using Photochemically Induced Fluorescence Detection. Analytical Letters, 1996; 29: 1447-1461.

Garcia-Campana AM, Aaron JJ, Bosque-Sendra JM. Micellarenhanced photochemically induced fluorescence detection of chlorophenoxyacid herbicides. Flow injection analysis of mecoprop and 2,4-dichlorophenoxyacetic acid. Talanta, 2001; 55: 531- 539.

Hu XL,Xu DP,Liu SP,Liu ZF,Li CX,Chen PL.Determination of meclofenoxate hydrochloride by resonance Rayleigh scattering method coupled with flow injection technique.Analytical Letters, 2010;43: 2125 2133.

International Conference on Harmonisation (ICH) of Technical Requirements for Registration of Pharmaceuticals for Human Use, Topic Q2 (R1): Validation of Analytical Procedures: Text and Methodology, Geneva, 2005.

Lang K, Lunák S. Photocatalytic degradation of 4chlorophenoxyacetic acid in the presence of an iron complex and hydrogen peroxide. Photochem Photobiol Sci, 2002;1: 588- 591.

Li K, Zhu X, Liang Y.Gold Nanoparticles/Carbon Nanotubes Composite Film Modified Glassy Carbon Electrode Determination of Meclofenoxate Hydrochloride. Pharmacology \& Pharmacy, 2012; 3: $275-$ 280 .
Ling-yun HE, Hong-peng XIA, Jian-ping WU, Ze-neng CHENG. Determination of meclofenoxate hydrochloride capsules by HPLC. Chinese Journal of Analysis Laboratory, 2007; 9: 74- 76.

Marcer D, Hopkins SM. The differential effects of meclofenoxate on memory loss in the elderly. Age Ageing, 1977; 6: 123131.

Ohta N, Yotsuyanagi T, Ikeda K. pH-Dependent degradation and stabilization of meclofenoxate hydrochloride by human serum albumin. Chem Pharm Bull, 1986; 34: 2585-2590.

Otsuka T, Yoshioka S, Aso Y, Terao T. Application of microcalorimetry to stability testing of meclofenoxate hydrochloride and $d l$ - $\alpha$-tocopherol. Chem Pharm Bull, 1994; 42: 130-132.

Schtissler W. Automatic Measurement of Bentazone and Phenoxy Acid Herbicides by HPLC with Three Different Detectors. Chromatographia, 1990; 29: 24- 30.

Shoukrallah I,Sakla A,Paletta B.Quantitative determination of some pharmaceuticals in bulk drugs and tablets by proton magnetic resonance (PMR) spectroscopy. Farmaco, 1990; 45: 455-463.

Sinko PJ. 2006. Martin's Physical Pharmacy and

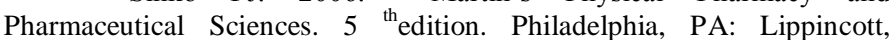
Williams and Wilkins, 401- 404.

Stahl M. 2003. Peak purity analysis in HPLC and CE using diode array technology. Waldbronn, Germany: Agilent Technologies.

Sweetman SC. 2009. Martindale-The Complete Drug Reference. $36^{\text {th }}$ edition,London, UK: The Pharmaceutical Press, 2338.

Tatsuhara T,Tabuchi F. Analysis of meclofenoxate and its degradation products by high performance liquid chromatography. Chem Pharm Bull, 1980; 28: 779-782.

Wood PL, Peloquin A. Increases in choline levels in rat brain elicited by meclofenoxate. Neuropharmacol,1982; 21:349- 354

Yoshioka S, Shibazaki T, Ejima A. Stability of solid dosage forms.I. Hydrolysis of Meclofenoxate Hydrochloride in the solid state. Chem Pharm Bull, 1982; 30: 3734-3741.

Yoshioka S, Shibazaki T, Ejima A. Stability of solid dosage forms. II. Hydrolysis ofMeclofenoxate Hydrochloride in Commercial tablets. Chem Pharm Bull, 1983;31: 2513-2517.

Zhang P, Liu T, Xu X, Liu S, Chen D. Determination of Meclofenoxate Content in Meclofenoxate Hydrochloride for Injection by DSC and 1H-NMR. American Journal of Analytical Chemistry, 2016; 7: 92-98.

\section{How to cite this article:}

Marwa Said Moneeb, Feda Elgammal, Suzy Mohamed Sabry., Development and validation of a stability indicating HPLC-diode array-fluorescence method for the determination of meclofenoxate hydrochloride and $p$-chlorophenoxyacetic acid. J App Pharm Sci, 2016; 6 (07): 001-011. 